\title{
Research on The Techniques of Dynamic Testing for Taxiway Bridge under Aircraft Taxiing
}

\author{
Xianmin Zhang ${ }^{1, a}$, Yan Yan ${ }^{2, b}$, Qian Dong ${ }^{3, c}$ \\ ${ }^{1}$ Civil Aviation University Of China,Dongli District,Tianjin,China \\ ${ }^{2}$ Civil Aviation University Of China,Dongli District,Tianjin,China \\ ${ }^{3}$ Tianjin University Of China,Nankai District,Tianjin,China \\ acauczxm@126.com, bcugeva@126.com, ${ }^{\text {'5 } 549841779 @ q q . c o m}$
}

Keywords: Taxiway Bridge,Dynamic Testing,Mechanical Properties,BDI,Non-destructive Testing Abstract. To resolve traffic conflicts, taxiway bridges are set in major airports. Taxiway bridges are different from highway bridges in load grades and structure types. The traditional test methods are short in two aspects: interrupting traffic, which seriously affects the normal operations of airport. And the second is all of them can not simulate actual load of aircraft to taxiway bridge. This paper gives a brief introduction to the technical research on mechanical properties of taxiway bridge, which is based on modal tests and aircraft loading tests. The result shows that this method can overcome the shortcomings of traditional test methods, and provides an effective method for rapid non-destructive testing on taxiway bridges.

\section{Introduction}

Taxiway bridge is much different from highway bridge[1]. First, different in load grade. Taking Boeing747-400 as an example, the load to taxiway bridge under aircraft taixiing is 20 times as heavy as the standard vehicle, but only 2.4 times to highway bridge in force bearing area. Second, different in structure type. To meet the requirement of airfoils' width, the width-span ratiois of taxiway bridge is much larger than that of highway bridge.

There are some shortcomings on traditional testing methods of taxiway bridge[2]: First, a large number of loading vehicles are needed in order to meet the load efficiency. Second, The load to the deck under aircraft taixiing is so complex, which is affected by deck roughness, aircraft lifting and other factors[3,4,5], that loading vehicles can't simulate the real load of aircraft loading on the deck. Third, the testing process lasts long and must be interrupted, that seriously affect the normal operations of airport. These deficiencies directly affect the accuracy and the effectiveness of testing results, the economy and the efficiency of testing processes.

Therefore, a new method is described in this paper for the dynamic testing of mechanical properties of taxiway bridge under aircraft taxiing, which provides a new technical support and project reference.

\section{Principle}

Considering the frequency collected and the strain influence lines measured by sensors set in modal tests and dynamic loading tests as the main amending basis for the model, the deform value as checking index, model parameters are ajusted reasonablely until the matching degree of finite element model is more than $95 \%$ with the measured value[6], namely that the amended finite element model is equivalent to the actual mechanical model of taxiway bridge.

Finally, the design load and the checking load are exerted on the amended finite element taxiway bridge model. The mechanical response of the bridge structure is calculated to be compared with the theoretical value, then the calibration coefficients of taxiway bridge is obtained. 


\section{Test programe}

Overview of taxiway bridge. The taxiway bridge is comprised of prestressed concrete continuous beams, which has 5 spans $(16 \mathrm{~m}+3 \times 20 \mathrm{~m}+16 \mathrm{~m})$. The deck of taxiway bridge is 65.5 meters long and the bottom of the one is 62.5 meters wide. The main beams are made of C50 cast-in-place prestressed concrete. The taxiway bridge is West-East trend, whose maximum taxiing weight is designed according to E class of aircraft. Boeing747-400 is taken as calculating load, Boeing777 and MD-11 are taken as checking loads.

Test load.Checking models are Boeing747-400, Boeing777 and MD-11.

Checking loads are taken to be as Eq. 1:

$\mathrm{F}=\mathrm{G}^{*} \mathrm{~K}$.

Where $\mathrm{F}$ represents checking load; $\mathrm{G}$ represents maximum taxiing weight; $\mathrm{K}$ represents load distribution coefficient of main undercarriage[7]. The specific values are shown in Table 1.

Table1 The specific values of checking loads.

\begin{tabular}{lll}
\hline Aircraft models & Maximum taxiing weight $(\mathrm{KN})$ & $\begin{array}{l}\text { Load distribution coefficient of main } \\
\text { undercarriage }\end{array}$ \\
\hline Boeing747-400 & 3978.0 & 0.952 \\
Boeing777 & 3411.0 & 0.938 \\
MD-11 & 2871.2 & 0.780 \\
\hline \hline
\end{tabular}

Sensor arrangement. The most unfavorable span is choosen as the test subject which is the first one in the west. The displacement sensors are located upon the deck, and the acceleration sensors are under the beam meanwhile the strain sensors are in the side of beam. Six different models, a total of ten aircrafts, are choosen to test the vibration response of the taxiway bridge. The arrangements of acceleration sensors, displacement sensors, strain sensors are shown as Fig. 1-Fig. 3.

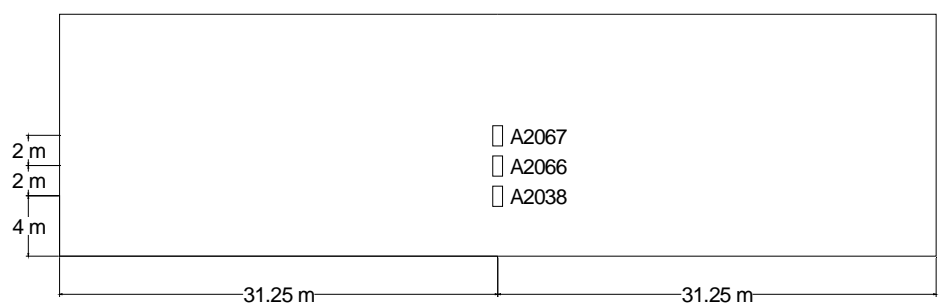

Fig. 1 Arrangement of accerlation sensors



Fig. 2 Arrangement of displacement sensors 


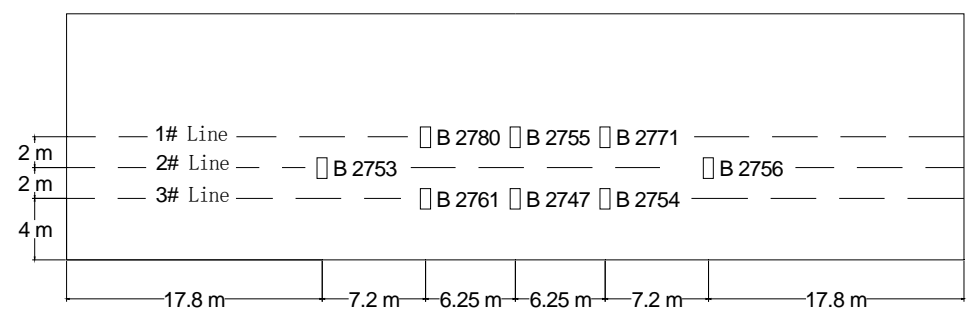

Fig. 3 Arrangement of strain sensors

\section{Analysis}

Analysis of modal test result. The acceleration data collected by the acceleration sensors is taken to calculate the modal data when processing data of modal test. The mode is displayed and the deform is calculated by analysising informathion of time domain and frequency domain, then the modal parameters of the structure are determined[8].

Through analysis of test data obtained by acceleration sensors, the first-order frequency of the taxiway bridge is $9.21 \mathrm{~Hz}$, spectrum analysis result and the first mode are shown in Fig. 4 and Fig. 5.

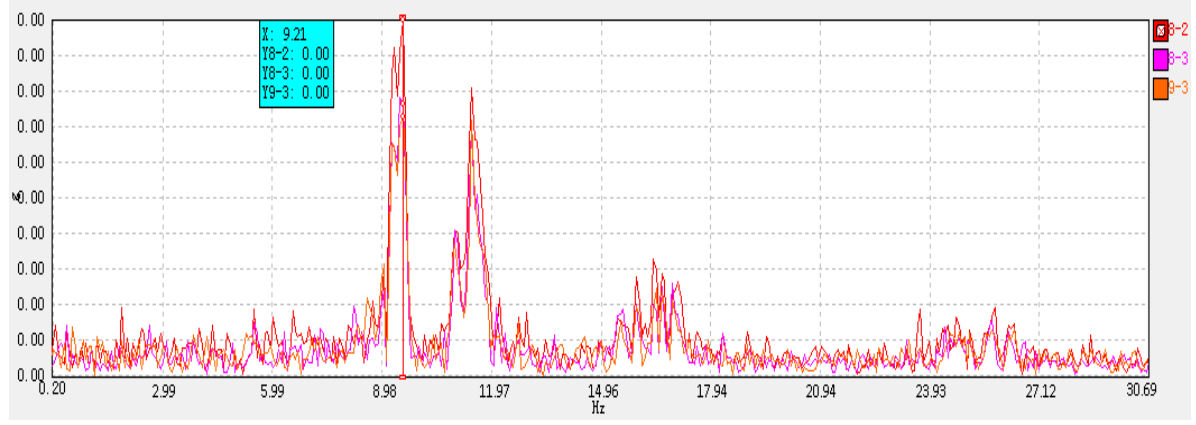

Fig.4 Spectrum analysis result

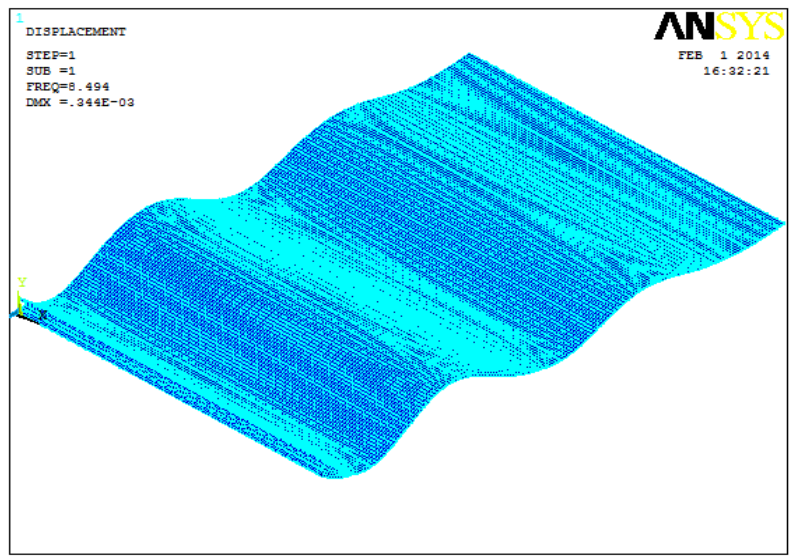

Fig. 5 First mode figure of taxiway bridge

Analysis of the result under aircraft taxiing. Six kinds of models (A321 / A319 / B738 / A320 /B73X / B73G), a total of ten aircrafts, are tested to measure the displacements of the taxiway bridge. One displace curve of A320 when taxiing on the taxiwaybridge is as Fig. 6-Fig. 8. 


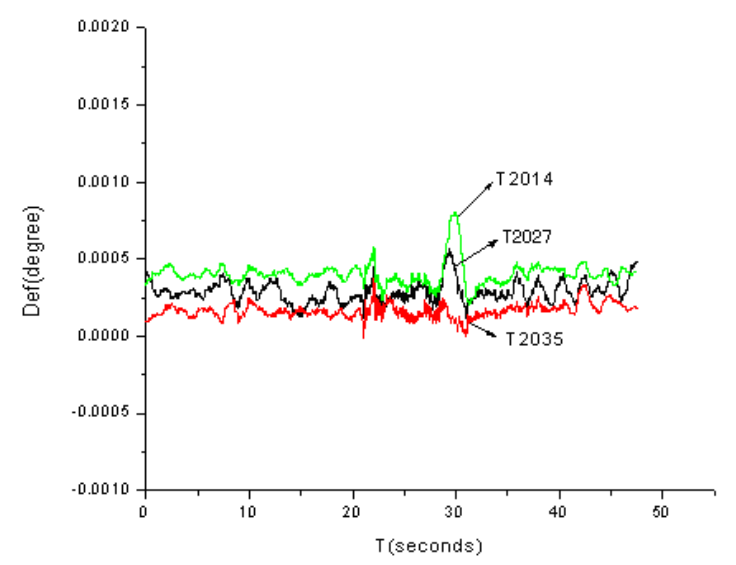

Fig. 6 1\# line of displacement curve of A320

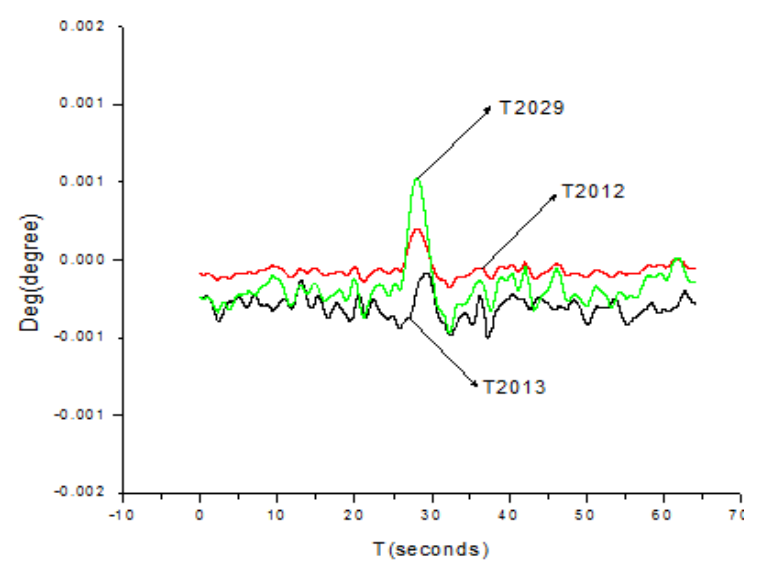

Fig. 8 3\#line of displacement curve of A321

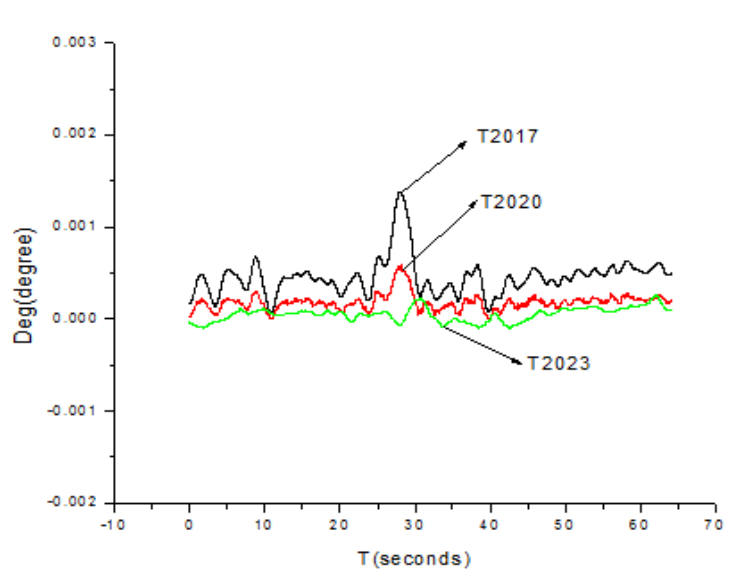

Fig. 7 2\# line of displacement curve of A320

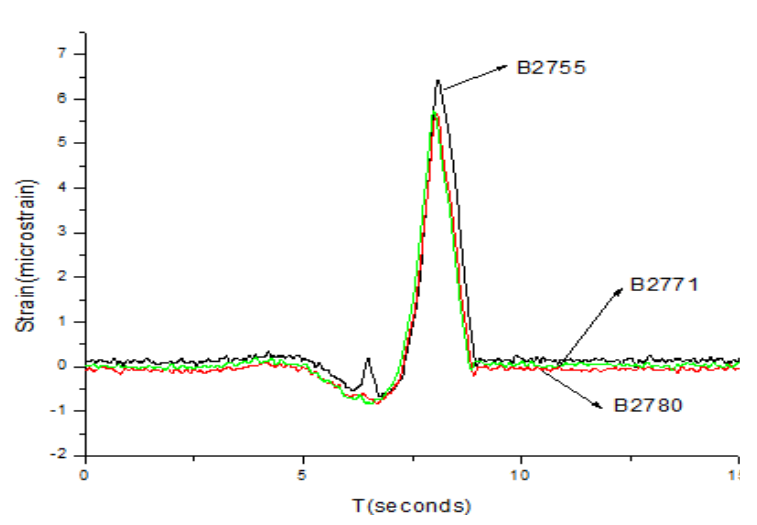

Fig. 9 1\# line of strain curve of A321

Six kinds of models (A321 / A319 / B738 / A320 /B73X / B73G), a total of ten aircrafts, are tested to obtain the bridge vibration response. One strain curve of A321 is shown as Fig. 9-Fig. 11.

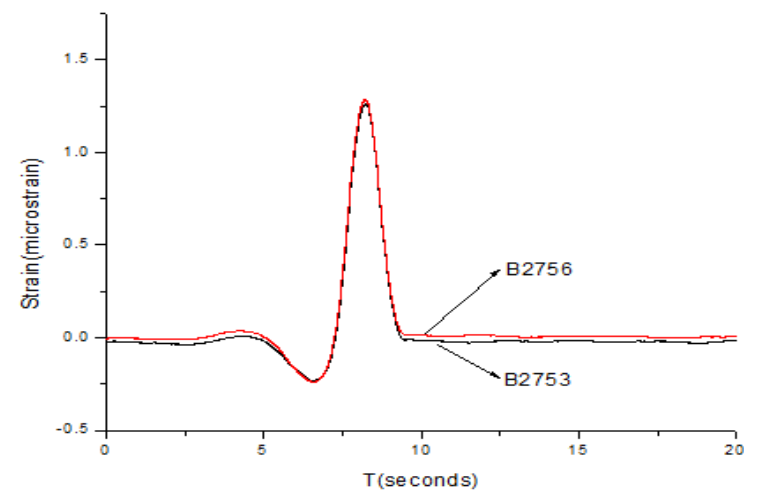

Fig 10. 2\# line of Strain curve of A321

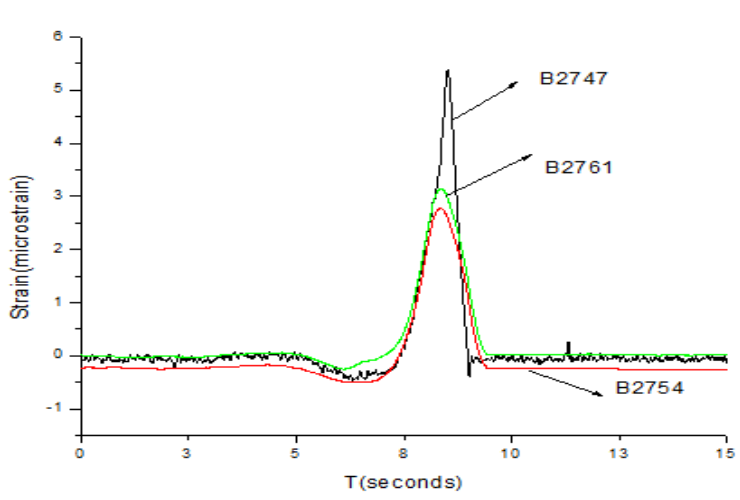

Fig 11. 3\# line of train curve of A320 
By deriving the simplify relation between IRI and power spectral density of the deck, and considering the average speed measured under aircraft taxiing, the dynamic load factor of aircraft on the deck is solved to be $\mathrm{K}=1.02[6]$.

The dynamic design load and checking load are applied to the actual finite element model established by the way shown in part 2 principle, which are equal to the value that static load are multiplied by the dynamic load factor. The mechanical response of the bridge structure is calculated to be compared with the theoretical value, the results are shown in Table 2-Table 7.

Table 2 Results of loading area in first span loaded by Boeing747-400

\begin{tabular}{lllll}
\hline \hline Setting & unit & calculated value & actual value & $\begin{array}{l}\text { Calibration } \\
\text { coefficients }\end{array}$ \\
\hline Displacement & $\mathrm{mm}$ & 0.77 & 0.70 & 0.90 \\
Strain & $\mu \varepsilon$ & 30.4 & 27.1 & 0.89 \\
\hline \hline
\end{tabular}

Table3 Results of loading area in second span loaded by Boeing747-400

\begin{tabular}{lllll}
\hline \hline Setting & unit & calculated value & actual value & $\begin{array}{l}\text { Calibration } \\
\text { coefficients }\end{array}$ \\
\hline Displacement & $\mathrm{mm}$ & 1.03 & 0.93 & 0.90 \\
Strain & $\mu \varepsilon$ & 32.8 & 29.8 & 0.91 \\
\hline \hline
\end{tabular}

Table4 Results of loading area in first span loaded by Boeing 777

\begin{tabular}{lllll}
\hline \hline Setting & unit & calculated value & actual value & $\begin{array}{l}\text { Calibration } \\
\text { coefficients }\end{array}$ \\
\hline Displacement & $\mathrm{mm}$ & 0.58 & 0.52 & 0.90 \\
Strain & $\mu \varepsilon$ & 21.5 & 18.8 & 0.87 \\
\hline \hline
\end{tabular}

Table 5 Results of loading area in second span loaded by Boeing 777

\begin{tabular}{lllll}
\hline Setting & unit & calculated value & actual value & $\begin{array}{l}\text { Calibration } \\
\text { coefficients }\end{array}$ \\
\hline Displacement & $\mathrm{mm}$ & 0.77 & 0.70 & 0.90 \\
Strain & $\mu \varepsilon$ & 23.0 & 21.3 & 0.93 \\
\hline \hline
\end{tabular}

Table 6 Results of loading area in first span loaded by MD-11

\begin{tabular}{lllll}
\hline \hline Setting & unit & calculated value & actual value & $\begin{array}{l}\text { Calibration } \\
\text { coefficient }\end{array}$ \\
\hline Displacement & $\mathrm{mm}$ & 0.41 & 0.37 & 0.90 \\
Strain & $\mu \varepsilon$ & 16.0 & 4.2 & 0.89 \\
\hline \hline
\end{tabular}

Table 7 Results of loading area in second span loaded by MD-11

\begin{tabular}{llclc}
\hline \hline Setting & unit & calculated value & actual value & $\begin{array}{l}\text { Calibration } \\
\text { coefficient }\end{array}$ \\
\hline Displacement & $\mathrm{mm}$ & 0.56 & 0.49 & 0.88 \\
Strain & $\mu \varepsilon$ & 17.5 & 15.7 & 0.90 \\
\hline \hline
\end{tabular}




\section{Conclusion}

All the information of all tested points, including acceleration, deform, and strain, can be obtained by tests, which is of large amount and high reliability to meet the test requirements.

The deck roughness, aircraft lifting and other factors are taken full account of when indoor finite element model is amended, the actual dynamic load under aircraft taxiing can be simulated.

A large amount of data by field tests is compared with the data calculated by the indoor finite element in this article, by constantly revising and iterative optimization, the real effective model of taxiway bridge is obtained, which is $95 \%$ matching with the calculated value.

The result shows that the actual dynamic mechanical properties of the bridge exceeds the theoretical value; The deform and strain of actual taxiway bridge calculated by design load are less than the one of design drawings. The calibration coefficients of taixway bridge in deform and strain are less than 1, which indicates that the actual taxiway bridge meets the design requirements.

A new way for the test of the mechanical properties of taxiway bridge under aircraft taxiing can be achieved in this paper, which is an effective testing method of taxiway brige without interrupting the traffic.

\section{References}

[1]Jefts.A.R: presented at Proceedings of the Eighth Conference on Electronic Computation, Houston,Texas,February21-23.(1983)

[2]Amit, G. \& Animesh, D: submitted to Nondestructive Testing and Evaluation. 23(2). pp. 121-140.(2008)

[3]Yao-zhi Lü, Qian Dong, and Chun-fei Hu : submitted to Journal of China \& Foreign Highway, vol. 33, pp. 74-77, In Chinese.(2013)

[4]Qingxiong $\mathrm{Wu}$, Baochun Chen, and Lingzhi $\mathrm{Xi}$, submitted to Journal of Traffic and Transportation Engineering, vol.8, pp. 36-41, February, In Chinese.(2008)

[5]Hong-duo Zhao, " Research on traffic load analysis method and related parameters of airport pavement design," Tongji Univ., Shang Hai, China.(2006)

[6]Yan-jun Li, “ Research on damage identification of bridge based on quasi-static load test”, Chongqing Jiaotong Univ., Chong Qing, China.(2014)

[7]MH/T5004-2010 Specifications for airport cement concrete pavement design, Civil Aviation Administration of China.(2010)

[8]Xiang-hua Tao, Xiao-ming Huang: submitted to J. o f HUST. (Urban Science Editio n), vol. 20, pp. 47-50, DecembeR, In Chinese.(2003) 